\title{
Analysis of Fire Statistics of China: Fire Frequency and Fatalities in Fires
}

\author{
FULIANG WANG, SHOUXIANG LU, and CHANGHAI LI \\ State Key Laboratory of Fire Science \\ University of Science and Technology of China \\ Hefei Anhui 230026, People's Republic of China
}

\begin{abstract}
This paper presents an analysis of fire statistical data for China between 1998 and 2002. Fire situation and fire characteristic have been discussed with the method of average analysis, dynamic analysis and factor analysis. Analysis reveals that the government's efforts to fire protection have succeeded to some extent. In addition, fire occurring likelihood (fire frequency) and fatalities in fires have been also analyzed. Based on previous analysis, fire frequency in different building categories and fire societal risk criterion has been presented.
\end{abstract}

KEYWORDS: fire statistical analysis, fire frequency, fatalities, fire societal risk

\section{INTRODUCTION}

China is a developing country with a population of some 1.3 billion people. Great changes and significant achievements have been taking place since the policy of reform and opening to the world. However, China shares many problems with other countries around the world, including the risk of fire incidents.

The increasing number of fire disasters recent years in China is causing nationwide and even worldwide attention. In order to reduce the risk of fire incidents, it is necessary to do some research on fire science and fire safety engineering. Fire statistical analysis is one of the most effective means. Fire statistics is completed by Fire Service Bureau, Ministry of Public Security in China. The results of fire statistical analysis can guide on decision making in fire risk management. Meanwhile, fire statistics supplies the research and application of fire science with mass of basic data. So fire statistics and analysis on fire statistics is of great importance.

With the development and application of quantified fire risk assessment and performance-based fire protection design method in China, fire statistics faces the new challenge such as quantifying fire occurrence likelihood and fire risk criterion through fire statistics analysis. At present, there is such lack of the study of quantifying fire occurrence likelihood and fire risk criterion in China that these data are often cited from other countries [1].

\section{FIRE STATISTICS SUMMARIZE}

The number of fire incidents in a year per person (R1), the number of fatalities in a fire incident (R2) and the number of fatalities per person in one year fire incidents (R3) are the most common fire risk indexes while referring one region or nation's fire risk. Table 1 has listed statistical results of those fire risk indexes for China, USA in 2000 and the globe in 2001. The average fire risk of China is distinctly different from that of USA and the globe. The number of fatalities in a fire incident (R2) of China is about one times 
more than that of the globe and six times more than that of USA. Though the number of fire incidents in a year per person (R1) and the number of fatalities per person in one year fire incidents (R3) of China is fewer than that of the globe and USA , the most important factor is that the huge population of China rather than the fewer fire incidents or fatalities.

Table 1. The fire risk indexes for China, USA and the entire world.

\begin{tabular}{l|c|c|r}
\hline \multicolumn{1}{c|}{ Scope of statistics } & China & USA & Globe [4] \\
\hline Year & 2000 & 2000 & 2001 \\
\hline Population (million) & $1266[2]$ & $281[3]$ & 6300 \\
\hline Number of fire incidents $\left(\times \mathbf{1 0}^{\mathbf{3}}\right)$ & $189.0[5]$ & $1708.0[6]$ & $8000.0^{*}$ \\
\hline Number of fatalities in fires & $3021[5]$ & $4045[6]$ & $75000^{*}$ \\
\hline R1 & $1.5 \times 10^{-4}$ & $6.2 \times 10^{-3}[6]$ & $1.3 \times 10^{-3}$ \\
\hline R2 & $1.6 \times 10^{-2}$ & $2.4 \times 10^{-3}$ & $9.4 \times 10^{-3}$ \\
\hline R3 & $2.4 \times 10^{-6}$ & $1.5 \times 10^{-5}[6]$ & $1.2 \times 10^{-5}$ \\
\hline * Esimated Value
\end{tabular}

Fire statistics [5] shows that the number of fire incidents and fire direct loss has been ascending with the rapid development of Chinese economy since the establishment of P.R. China (1949), as shown in Fig. 1. Between 1981 and 1990, the average number of fire incidents was about 38 thousand and average fire direct loss was about 360 million Yuan, between 1991 and 2000, the average number of fire incidents was about 89 thousand and average fire direct loss was about 1160 million Yuan. The number of fire incidents and fire direct loss respectively increased 134.2 percent and 222.2 percent compared with those of last ten years. Though the fire frequency and fire loss has been rising rapidly since 1980s, the fatalities and injuries in fires have leveled off, as shown in Fig. 2.

The relationship between fire and socioeconomic factors is of great significance for fire prediction, fire protection and fire risk assessment. Economy is one of the most important socioeconomic factors. The Fig. 3 shows the variation of fire situation with the economic growth.

As shown in Fig. 3, the number of fire incidents and fire direct loss has been increasing along with the economic growth. However, the ratio between fire direct loss and Gross National Product in China presents descending tendency in recent years, which means that the government's efforts to fire protection have succeeded to some extent.

The number of fire incidents in recent five years (1998-2002) is between $1.4 \times 10^{5}$ and $2.6 \times 10^{5}$ times every year in China. The average number of fatalities in fire is about 2500 each year. Table 2 has listed the basic statistic data of fire incidents between 1998 and 2002. The previous statistical results indicate that the number of fire incidents and fire direct loss in China may keep on ascending and the fire risk may be on relatively high level. 


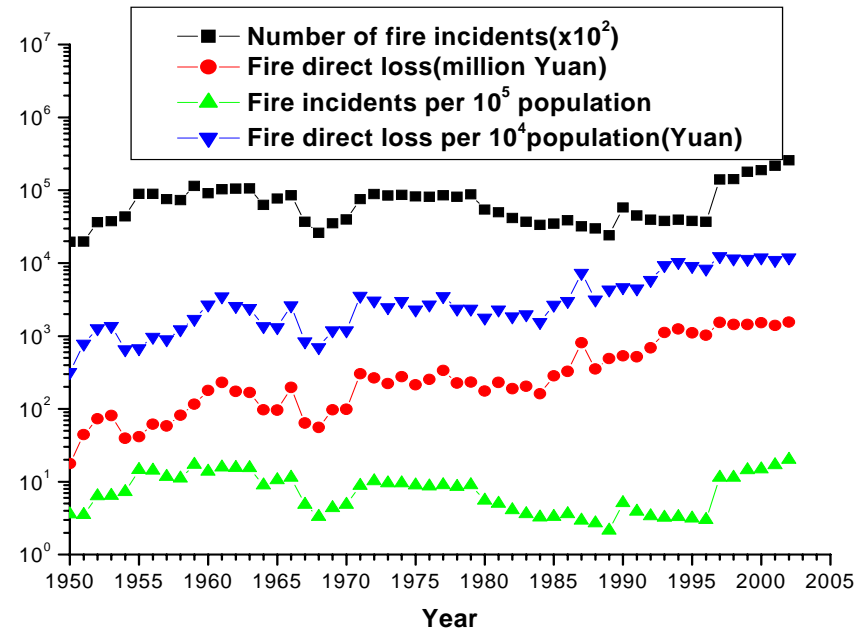

Fig. 1. Number of fire incidents and fire direct loss between 1950 and 2000 (Data from [5]).
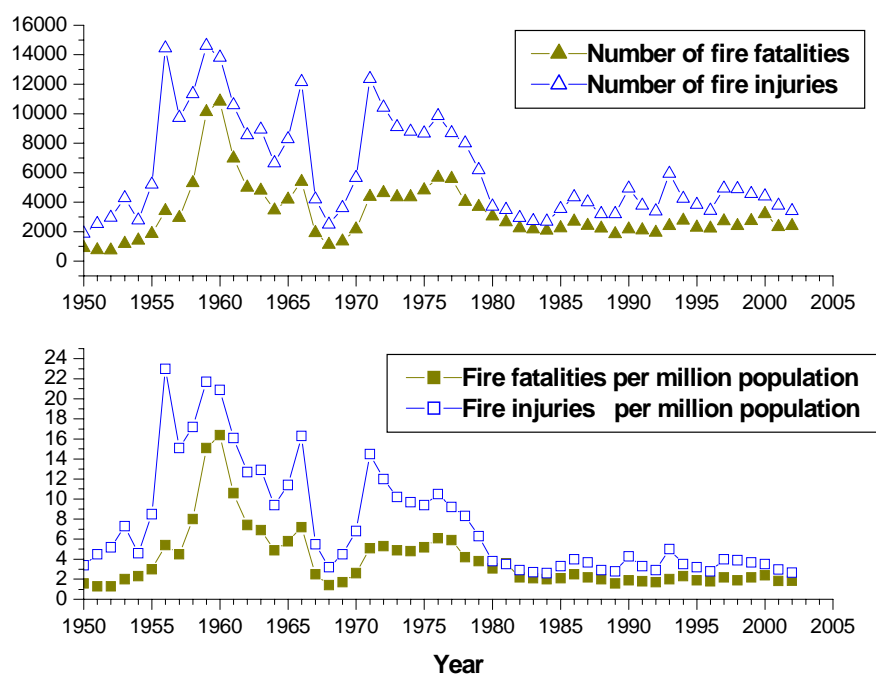

Fig. 2. Fatalities and injuries in fires between 1950 and 2000 (Data from [5]). 


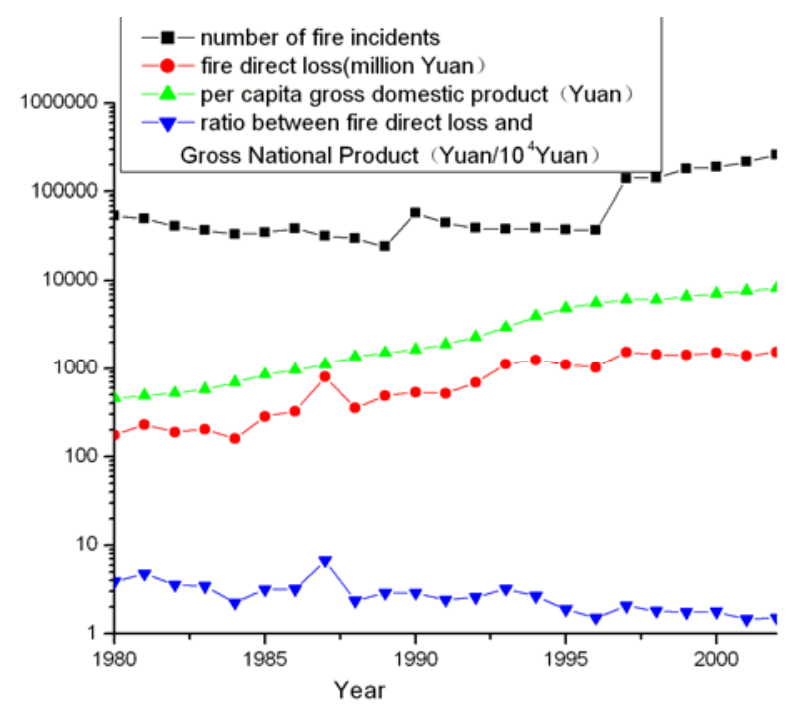

Fig. 3. Relationship between fire incidents and economy factor (Data from [2,5]).

Table 2. Fire situation summaries (1998-2002) [5].

\begin{tabular}{|l|c|c|c|r|}
\hline Year & $\begin{array}{c}\text { The number of } \\
\text { fire incidents }\end{array}$ & $\begin{array}{c}\text { Fatalities } \\
\text { (person) }\end{array}$ & $\begin{array}{c}\text { Injuries } \\
\text { (person) }\end{array}$ & $\begin{array}{c}\text { Direct loss } \\
\text { (million Yuan) }\end{array}$ \\
\hline 1998 & 142326 & 2389 & 4905 & 1442.6 \\
\hline 1999 & 179955 & 2744 & 4572 & 1433.9 \\
\hline 2000 & 189185 & 3021 & 4404 & 1522.2 \\
\hline 2001 & 216784 & 2334 & 3781 & 1403.3 \\
\hline 2002 & 258315 & 2393 & 3414 & 1544.5 \\
\hline Sum & 986565 & 12881 & 21076 & 7346.4 \\
\hline
\end{tabular}

\section{FIRE FREQUENCY ANALYSIS AND FIRE FREQUENCY IN DIFFERENT BUILDING CATEGORIES}

\section{Impact Factors Analysis of Fire Frequency}

Fire frequency can be affected by many factors. These factors mainly include:

- Fire loads' size, distribution, continuity, porosity and combustion performance

- Buildings' ventilation condition

- Buildings' physical dimension

- Building categories

- Buildings' total area

- Meteorological factor

- Building occupies' educated level

Figure 4 shows the number of fire incidents in different month. Statistical data (19982002) indicates that the number of fire incidents in different month is distinctly different. Fire incidents occur most frequently in winter and spring, especially in February (15.6\%); Fire incidents occur relatively fewer in summer and autumn, especially in August (5.2\%). 
The feature mentioned above is caused by meteorological factor in China. Because of the difficulty of obtaining data, the remnant factors haven't been described in addition here.

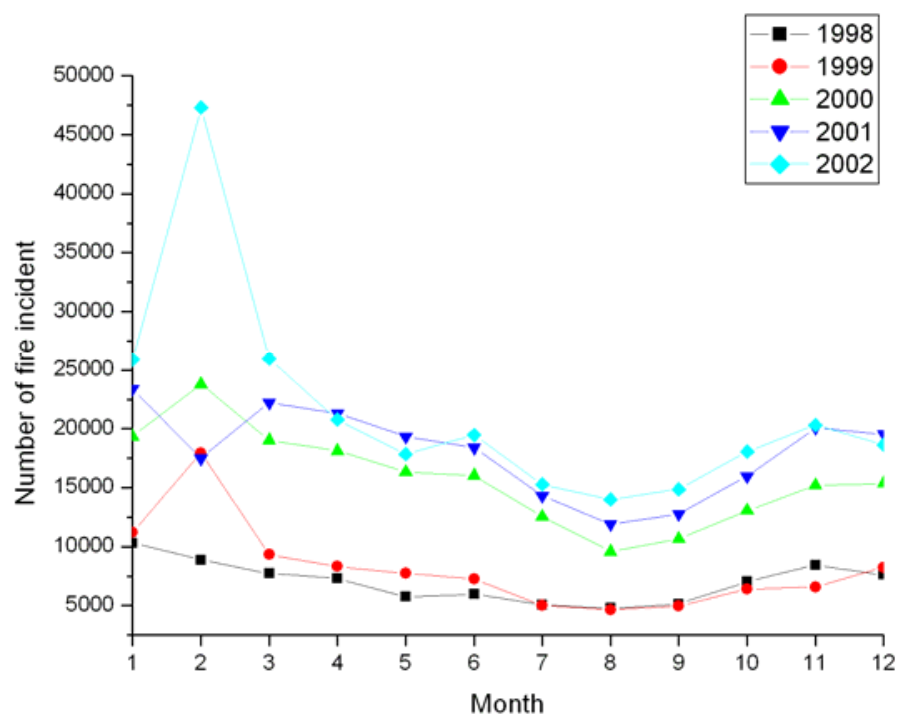

Fig. 4. Relationship between fire frequency and meteorological factor (Data from [5,7]).

\section{Fire Frequency in Different Building Categories}

Fire frequency is needed as one of initial inputs for risk analysis used in performancebased fire safety design. Considering convenience of quantifying fire frequency and the statistic data's limit, building categories is one and only factor considered during fire frequency determination in this paper. Buildings' area statistic data quotes the references [2] and [8]. The analysis results are presented in Table 3. Results from Japan [9] are also shown in Table 3. It is obvious that fire frequency (/year•m2) for residential building in China is about half of that for residential building in Japan. One of the reasons might be that the timbering residential buildings are more common in Japan than in China.

Table 3. Fire frequency in different building categories in China and Japan.

\begin{tabular}{l|c|r}
\hline \multirow{2}{*}{ Building categories } & \multicolumn{2}{|c}{ Fire frequency $\left(\right.$ year•m ${ }^{2}$ ) } \\
\cline { 2 - 3 } & China & Japan [9] \\
\hline Residential building & $3.33 \times 10^{-6}$ & $6.46 \times 10^{-6}$ \\
\hline Place of amusement & $5.28 \times 10^{-5}$ & - \\
\hline Cinema & $1.31 \times 10^{-5}$ & - \\
\hline Museum & $4.55 \times 10^{-6}$ & - \\
\hline Office & - & $6.67 \times 10^{-7}$ \\
\hline Shopping center & - & $4.12 \times 10^{-6}$ \\
\hline
\end{tabular}


Note: Considering that new management regulations for fire statistics have been in operation since 1997 in China and the difficulty of fire statistics collection, the fatalities data used in sequel part of this paper are cited from fire statistics between 1998 and 2002. In addition, the nationwide fire statistics presented in this paper doesn't include the data of the Hong Kong Special Administrative Region, Macao Special Administrative Region, and Taiwan province.

\section{ANALYSIS OF FATALITIES IN FIRES AND FIRE SOCIETAL RISK CRITERION}

\section{Significance of Establishing Fire Societal Risk Criterion}

With the development of fire safety engineering and performance-based fire protection design method, the importance of quantified fire risk assessment is increasing. Quantified method can handle uncertainty analysis more easily than qualitative method. However the question "how safe is safe enough" must be answered before quantified risk assessment is put in practice. In order to make full use of the advantages of quantified method, it is necessary to establish quantified societal risk criterion.

It is lack of research on fire societal risk criterion in China. At present, there are no quantified criteria on fire societal risk in China. In the application of quantified fire risk assessment technology, fire societal risk criterion is usually established according to other countries' societal risk criteria, which is presented in the use of FN diagrams. This paper focuses on the analysis of fire frequency and fatalities data of China and the establishment of fire societal risk criteria which are suitable for China.

\section{Fire Fatalities Analysis Based on Recent Years’ Statistical Data}

The results of fire fatalities analysis are often presented in graphical form. Such graphs are normally 'log-log' plots with the $\mathrm{x}$-axis representing the consequences (the number of fatalities $(\mathrm{N})$ ) and the y-axis representing their likelihood of occurrence $(\mathrm{F})$, which are referred to as FN curve. FN curves are a graphical presentation of information about the frequency of fatal accidents in a system and the distribution of the numbers of fatalities in such accidents. The frequency $\mathrm{F}(\mathrm{N})$ of accidents with $\mathrm{N}$ or more fatalities is plotted on FN graphs, where $\mathrm{N}$ ranges upward from 1 to the maximum possible number of fatalities in the system. Since the values of both $\mathrm{F}$ and $\mathrm{N}$ sometimes range across several orders of magnitude, FN graphs are usually drawn with logarithmic scales.

The fire fatalities analysis results have been shown in Fig. 5 and Table 4. Table 4 shows an analysis of fire incidents that occurred through 1998 to 2002 in China. Ni (i =1, 2, 3 ...) is the death numbers per fire incident. The fire incidents from N1 (one death) to N309 (309 deaths) are classified into twenty one groups in this table. As we have known, N1 is the most common case and takes the value of 5625 for these five years. In this period, there are 34 fire incidents with more than 10 fatalities, 8 fire incidents with more than 20 fatalities and 3 fire incidents with more than 30 fatalities. The 309 death case (N309) refers to the tragic Dong-du shopping center fire in 2000. It is obvious that the fatalities are distributed up to the number of order 30 except the catastrophic case. 


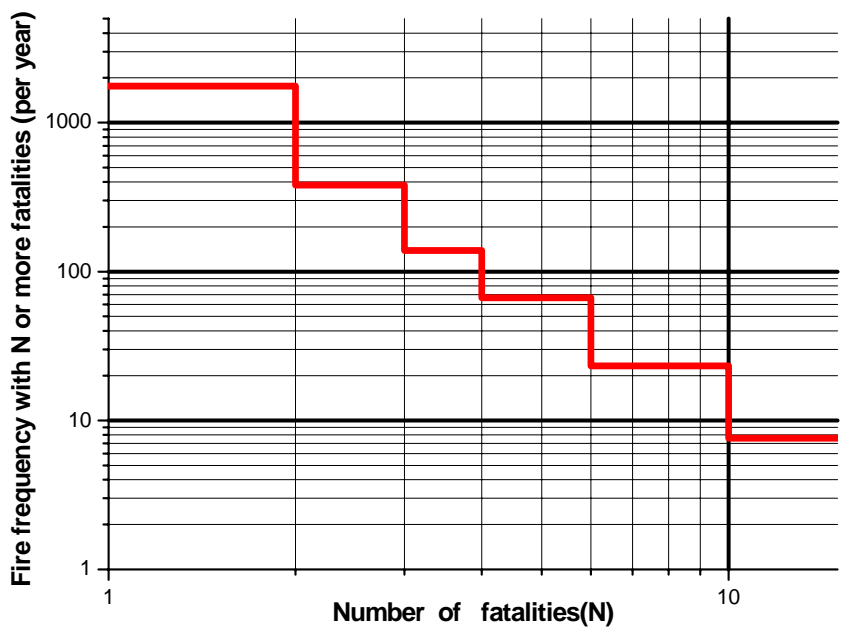

Fig. 5. Average FN curve of fire incidents between 1998 and 2002 (Data from [5,7]).

Table 4. Fatalities in fire incidents through 1998 to 2002 in China [5,7].

\begin{tabular}{|c|c|c|c|c|c|c|}
\hline \multicolumn{2}{|c|}{ Year } & 1998 & 1999 & 2000 & 2001 & 2002 \\
\hline \multicolumn{2}{|c|}{ Total number of fires } & 142326 & 179955 & 189185 & 216784 & 258315 \\
\hline \multicolumn{2}{|c|}{ Fatalities in fires } & 1631 & 1908 & 1883 & 1773 & 1759 \\
\hline \multirow{21}{*}{$\mathbf{N i}$} & $\mathrm{N} 1$ & 1242 & 1499 & 1483 & 1338 & 1401 \\
\hline & N2 & 236 & 250 & 268 & 228 & 234 \\
\hline & N3 & 78 & 82 & 63 & 85 & 70 \\
\hline & $\mathrm{N} 4+\mathrm{N} 5$ & 47 & 49 & 42 & 36 & 40 \\
\hline & $\begin{array}{l}\mathrm{N} 6+\mathrm{N} 7+\mathrm{N} 8+ \\
\mathrm{N} 9\end{array}$ & 21 & 15 & 18 & 83 & 11 \\
\hline & N10 & 1 & 4 & 1 & 1 & 0 \\
\hline & N11 & 2 & 0 & 0 & 0 & 0 \\
\hline & N12 & 1 & 0 & 1 & 0 & 0 \\
\hline & N13 & 1 & 1 & 2 & 1 & 0 \\
\hline & N14 & 1 & 2 & 0 & 0 & 0 \\
\hline & N15 & 0 & 1 & 1 & 0 & 0 \\
\hline & N16 & 0 & 1 & 0 & 0 & 0 \\
\hline & N17 & 0 & 0 & 1 & 0 & 1 \\
\hline & N18 & 0 & 0 & 0 & 0 & 0 \\
\hline & N19 & 0 & 1 & 0 & 0 & 1 \\
\hline & N20 & 0 & 1 & 0 & 0 & 0 \\
\hline & N24 & 1 & 2 & 0 & 0 & 0 \\
\hline & N25 & 0 & 0 & 0 & 1 & 1 \\
\hline & N38 & 0 & 0 & 1 & 0 & 0 \\
\hline & N74 & 0 & 0 & 1 & 0 & 0 \\
\hline & N309 & 0 & 0 & 1 & 0 & 0 \\
\hline \multicolumn{2}{|c|}{ Sum } & 2389 & 2744 & 3021 & 2334 & 2393 \\
\hline
\end{tabular}




\section{Establishment of Fire Societal Risk Criteria for China}

The concept of societal risk is complex and it is important to clarify what is under discussion. This is due to a wider problem in dealing with risk issues, since the precise meaning of risk terminology in general appears still to be substantially rooted in an individual's professional background. Historically, the term societal risk has been related to the impacts, usually upon people, associated with accidents. However, in recent years, there has been a tendency to consider the 'broader' picture. Fire societal risk here is defined as societal concern due to the occurrence of multiple fatalities in a single fire accident, which mainly consists of number of fatalities and fire frequency.

Fire risk to life safety includes individual risk and societal risk at least [10]. Individual risk (IR) can be broadly defined as the frequency at which an individual or group of individuals may be expected to sustain a given level of harm (typically, death or serious injury) from the realization of a fire accident. Societal risk can be measured with the frequency of harm at defined level to all occupants or a particular part of occupants when fire occurs. FN curves are used to illustrate fire societal risk in this paper.

Based on the data in Table 4, the frequency $\mathrm{F}(\mathrm{N})$ of fire incidents with $\mathrm{N}$ or more fatalities can be obtained. To be attention, the value of $F(N)$ used in subsequent context has been divided by the number of people exposing to fire incidents for application's convenience. In this paper, societal risk criteria are generally presented as 'lines' on FN plots. Mathematically, such expressions may be presented as [11]:

$$
F \times N^{\alpha}=r
$$

Where, $\mathrm{F}=$ the likelihood of $\mathrm{N}$ or more fatalities, $\mathrm{N}=$ the number of fatalities, $\alpha=$ 'aversion' factor, $r=$ constant.

Through logarithmic transformation, Eq. 1 can be presented as:

$$
\lg F_{N}=-\alpha \lg N+\lg r
$$

The undetermined coefficient including $\alpha$ and lgr can be determined using regression analysis method. The results of regression analysis have been listed in Table 5.

Table 5. Regression analysis results.

\begin{tabular}{l|c|c|c|c}
\hline Coefficient & $\begin{array}{c}\text { Estimated } \\
\text { value }\end{array}$ & $\begin{array}{c}\text { Standard } \\
\text { error }\end{array}$ & $\begin{array}{c}\text { 95\% confidence } \\
\text { interval }\end{array}$ & Significance \\
\hline$\alpha$ & 1.932 & 0.083 & $(1.767,2.097)$ & $\mathrm{P}(|\mathrm{t}| \geq \mathrm{t})<0.0001$ \\
\hline $\operatorname{lgr}$ & -5.700 & 0.091 & $(-5.880,-5.520)$ & - \\
\hline
\end{tabular}

standard deviation $=0.334$

The results of regression analysis can be used in prediction. Furthermore, based on "ALARP" principle, suppose 95\% confidence level as the tolerable fire societal risk, the risk criteria can be established, as shown in Table 6 and Fig. 6. 
Table 6. Fire societal risk criteria.

\begin{tabular}{l|c}
\hline \multicolumn{1}{c|}{ Risk Classification } & Risk Criteria Line \\
\hline ALAR upper limit & $\lg F_{N}=-1.932 \lg N-5.035$ \\
\hline Average standard line & $\lg F_{N}=-1.932 \lg N-5.700$ \\
\hline neglectable Risk upper limit & $\lg F_{N}=-1.932 \lg N-6.365$ \\
\hline
\end{tabular}

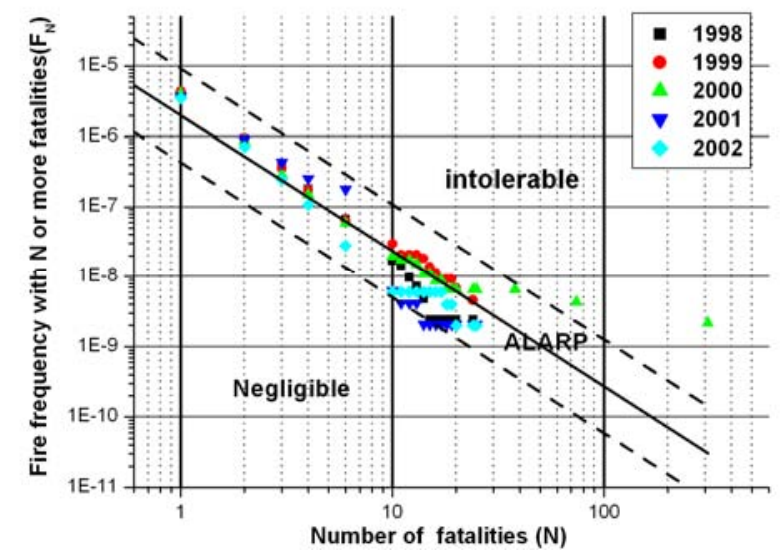

Fig. 6. FN-graph of fire societal risk criteria.

\section{CONCLUSIONS}

By analyzing fire statistics of China in recent years (1998-2002), the following problems have been discussed in this paper.

(1) Fire situation of China has been described based on the analysis of fire statistics through 1998 to 2002. The number of fire incidents and fire direct loss in China may keep on ascending and the fire risk may be on relatively high levels. However, the fatalities and injuries in fires have leveled off and the ratio between fire direct loss and Gross National Product presents descending tendency in recent years.

(2) Fire frequency in different building categories has been determined.

(3) Fire societal risk criterion has been established using FN curves and regression analysis method.

\section{ACKNOWLEDGEMENTS}

This paper was supported by National Basic Research Program of China (Grant No: 2001CB409600). The authors deeply appreciate the support.

\section{REFERENCES}

[1] Fan Weicheng, Liao Guangxuan, and Zhong Maohua, "Today's and Tomorrow's Fire Science in China,” China Safety Science Journal, 10, pp. 13, (2000). 
[2] National Bureau of Stistics of China, China Statistical Yearbook, Beijing, China Statistics Press, Chapter 10, 2003, (in Chinese).

[3] The U.S. Census Bureau, “America at the Dawn of a New Century,” Population Profile of the United States, 2000, Chapter 1.

[4] Liu Wanchen, "Fire Risk Trends and Control," Fire Technique and Products Information, 200, pp. 52-55, 2004, (in Chinese).

[5] Fire Service Bureau, Ministry of Public Security, Fire statistical yearbook of China, Beijing, Personal Press, pp.4-36, 2000-2003, (in Chinese).

[6] Karter, M.J., "Fire Loss in the United States During 2000," National Fire Protection Association, Quincy, MA, 2001, p.18.

[7] Fire Service Bureau, Ministry of Public Security, Fire statistical yearbook of China, Beijing, Publishing Company of Renmin Police, University of China, 1999, pp.4-36, (in Chinese).

[8] Department of Planning and Finance, Ministry of Culture of China, China Culture and Cultural Relic Statistical Yearbook, Beijing Library Press, 2002, (in Chinese).

[9] Sun Jinhua, Sun Zhanhui, Lu Shouxiang, Fan Weicheng, "Collapse Probability of Building Caused by Fire,” Engineer Science, 5, (11), p. 54, 2003, (in Chinese).

[10] Fan Weicheng, Sun Jinhua and Lu Shouxiang, Fire Risk Assessment Methodology, Beijing, Science Press, 2004, (in Chinese).

[11] Ball, D.J., and Floyd, P.J., “Societal Risks,” HSE Final Report, 1998, pp. 43-46. 